\title{
Adhesion of conventional and self-adhesive resin cements to indirect resin composite using different surface conditioning methods
}

\author{
Cilingir, Aylin ; Bilhan, Hakan ; Cilingir, Altug ; Gomec, Yavuz ; Ȯzcan, Mutlu
}

\begin{abstract}
This study evaluated the adhesion of conventional and self-adhesive resin cements to indirect resin composite (IRC) using different surface conditioning methods. Cylindrical IRC specimens $(\mathrm{N}=192)$ were randomly assigned to four surface conditioning methods ( $\mathrm{n}=8$ per group): (a) Control group, (b) Hydrofluoric acid, (c) Tribochemical silica-coating, and (d) $50 \mu \mathrm{m}$ Al2O3 air-abrasion. Specimen surfaces were finished using silicon carbide papers up to 600 grit under water irrigation, rinsed and dried. Direct composite blocks were bonded to IRC specimens using three conventional resin cements (Multilink, Panavia F2.0, and Resicem) and three selfadhesive resin cements (RelyX U100, Gcem, Speed Cem). Specimens were subjected to shear bond strength test in a Universal Testing Machine $(0.5 \mathrm{~mm} / \mathrm{min})$. Failure types were categorized as mixed, adhesive and cohesive. Data were analyzed using 2-way ANOVA and Tukey's tests. Two-parameter Weibull modulus, scale (m) and shape $(0)$ were calculated. The bond strength results $(\mathrm{MPa})$ were significantly affected by the surface conditioning method $(\mathrm{p}<0.0001)$ and cement type $(\mathrm{p}<0.001)$. For Panavia F2.0, Resicem, air-abrasion with $50 \mu \mathrm{m} \mathrm{Al} 2 \mathrm{O} 3$ significantly increased the results $(22.6 \pm 6.5,26.2 \pm 6.5$, respectively) compared to other conditioning methods (13.6 $\pm 1.4-21.9 \pm 3.1)$ but for Multilink, hydrofluoric acid etching $(20.5 \pm 3.5)$ showed significantly higher results $(\mathrm{p}<0.01)$. For the self-adhesive resin cements, air-abrasion with $50 \mu \mathrm{m} \mathrm{Al} 2 \mathrm{O} 3$ significantly increased the results compared to other conditioning methods, except for RelyX U100 ( p < 0.05). After air-abrasion with Al2O3, Gcem, (11.64), RelyX U100 (9.05), and SpeedCem (8.29) presented higher Weilbul moduli. Exclusively cohesive failure in the IRC was observed with RelyX U100 and Speedcem after Al2O3 air-abrasion.
\end{abstract}

DOI: https://doi.org/10.1080/01694243.2016.1215763

Posted at the Zurich Open Repository and Archive, University of Zurich

ZORA URL: https://doi.org/10.5167/uzh-146600

Journal Article

Accepted Version

Originally published at:

Cilingir, Aylin; Bilhan, Hakan; Cilingir, Altug; Gomec, Yavuz; Ȯzcan, Mutlu (2017). Adhesion of conventional and self-adhesive resin cements to indirect resin composite using different surface conditioning methods. Journal of Adhesion Science and Technology, 31(4):358-368.

DOI: https://doi.org/10.1080/01694243.2016.1215763 
Adhesion of conventional and self-adhesive resin cements to indirect resin composite using different surface conditioning methods

\author{
Aylin Cilingir, DDS, $\mathrm{PhD}^{\mathrm{a}}$ / Hakan Bilhan, DDS, $\mathrm{PhD}^{\mathrm{b}}$ / Altug Cilingir, DDS, $\mathrm{PhD}^{\mathrm{d}}$ / \\ Yavuz Gomec, MSc, Ph.Dc/ Mutlu Özcan, DDS, Dr.med.dent., PhDe
}

assistant Professor, Trakya University, Faculty of Dentistry, Department of Restorative Dentistry, 22030 Edirne , Turkey

${ }^{b}$ Associate Professor, Okan University, Faculty of Dentistry, Department of Prosthodontics, 34959 Tuzla, Istanbul, Turkey

${ }^{c}$ Associate Professor, Istanbul Technical University, Faculty of Mechanical Engineering, 34437 Gümüșsuyu, Istanbul, Turkey

'Professor, Istanbul University, Faculty of Dentistry, Department of Restorative Dentistry, 34093 Çapa, Istanbul, Turkey

eProfessor, University of Zürich, Dental Materials Unit, Center for Dental and Oral Medicine, Clinic for Fixed and Removable Prosthodontics and Dental Materials Science, Zürich, Switzerland

Correspondance to: Dr. Aylin Cilingir, Trakya University, Faculty of Dentistry, Department of Restorative Dentistry, Edirne, Turkey. e-mail: aylincinar@hotmail.com Tel.: +90-532-4457648 Fax: $+90-284-2364550$ 
Abstract: This study evaluated the adhesion of conventional and self-adhesive resin cements to indirect resin composite (IRC) using different surface conditioning methods. Cylindrical IRC specimens $(N=192)$ were randomly assigned to four surface conditioning methods ( $n=8$ per group): a) Control group, b) Hydrofluoric acid, c) Tribochemical silica-coating and d) $50 \mu \mathrm{m} \mathrm{Al}_{2} \mathrm{O}_{3}$ air-abrasion. Specimen surfaces were finished using silicon carbide papers up to 600 grit under water irrigation, rinsed and dried. Direct composite blocks were bonded to IRC specimens using three conventional resin cements (Multilink, Panavia F2.0 and Resicem) and three selfadhesive resin cements (RelyX U100, Gcem, Speed Cem). Specimens were subjected to shear bond strength (SBS) test in a Universal Testing Machine $(0.5 \mathrm{~mm} / \mathrm{min})$. Failure types were categorized as mixed, adhesive and cohesive. Data were analyzed using 2-way ANOVA and Tukey`s tests. Two-parameter Weibull modulus, scale $(m)$ and shape (0) were calculated. The bond strength results (MPa) were significantly affected by the surface conditioning method $(p<0.0001)$ and cement type $(p<0.001)$. For Panavia F2.0, Resicem, air-abrasion with $50 \mu \mathrm{m} \mathrm{Al}_{2} \mathrm{O}_{3}$ significantly increased the results $(22.6 \pm 6.5,26.2 \pm 6.5$, respectively) compared to other conditioning methods (13.6 $\pm 1.4-21.9 \pm 3.1)$ but for Multilink, hydrofluoric acid etching (20.5 \pm 3.5$)$ showed significantly higher results $(p<0.01)$. For the self-adhesive resin cements, air-abrasion with $50 \mu \mathrm{m} \mathrm{Al} \mathrm{O}_{3}$ significantly increased the results compared to other conditioning methods, except for RelyX U100 (p<0.05). After air-abrasion with $\mathrm{Al}_{2} \mathrm{O}_{3}$, Gcem, (11.64), RelyX U100 (9.05) and SpeedCem (8.29) presented higher Weilbul moduli. Exclusively cohesive failure in the IRC was observed with RelyX U100 and Speedcem after $\mathrm{Al}_{2} \mathrm{O}_{3}$ air-abrasion.

Keywords: Adhesion; resin cements; self-adhesive cement; surface conditioning; indirect resin composite 


\section{Introduction}

Polymerization shrinkage ranging from 1.5 to $3 \%$ is a major problem in dental adhesive filling techniques [1]. The shrinkage forces produce stresses that can exceed the cohesive strengths of the restorative materials yielding to microleakage that could cause secondary caries, pulpal irritation, postoperative sensitivity and marginal discoloration [1]. In order to overcome the problem of polymerization shrinkage and related microleakage in direct restorations, indirect restorations such as inlays or onlays made of ceramics or indirect resin composites (IRC) are proposed, where the latter is less costly [2].

IRC materials contain silanized micro-hybrid inorganic fillers embedded in a photopolymerizable organic resin matrix and are considered as alternative materials to direct resin composites due to their improved wear resistance, degree of conversion, water absorption, polymerization shrinkage and high fracture strength $[3,4]$. Laboratory processed and polymerized IRCs present high degree of conversion resulting in less residual unreacted methacrylic groups available for bonding [5]. High degree of conversion of IRCs is a result of heat, light and pressure application during polymerization that also results in increased mechanical properties but decreased bond strength. This may have consequences on the longevity of IRC restorations since the success and survival of such restorations depends on bonding of the cements to both the tooth structures and the restorative material. Typically, prior to application of the resin cement to the intaglio surfaces of the IRC restoration, the surface needs to be conditioned using air-abrasion, tribochemical silica coating, hydrofluoric acid etching or silane coupling agents alone or in combination. The methods based on air-abrasion create rough surface [6-9], while silane generates a 
chemical adhesion between the inorganic fillers and the organic matrix of the adhesive resin and the IRC $[6,10-12]$. Air-abrasion methods using alumina or alumina particles coated with silica were reported to deliver favourable adhesion results between direct resin composites to composite [13] or resin composite to IRC materials for repair purposes [14]. On the other hand, although hydrofluoric acid is known to be effective in etching silica-based ceramics [15,16], its effect on different filler particles of resin materials and improved adhesion of resin materials to the IRCs is controversial [7$9,16]$.

Limited information is available on the adhesion between IRCs and resin cements. Moreover, the use of self-adhesive resin cements does not require surface conditioning methods. Thus, their adhesion to non-conditioned IRCs is not known.

The objectives of this study therefore were to evaluate the adhesion of conventional and self-adhesive resin cements to IRCs using different surface conditioning methods and to analyze the failure types after debonding. The null hypothesis tested were that a) the type of surface conditioning method and b) resin cement would not show significant difference in bond strength.

\section{Materials and Methods}

The brands, manufacturers, chemical compositions and batch numbers of the materials used in this study are listed in Table 1.

Specimen preparation

IRC (Gradia Indirect, GC America, Tokyo, Japan) specimens were prepared (N=192, $\mathrm{n}=8$ ) a cylindrical silicone mould $(5 \mathrm{~mm} \times 5 \mathrm{~mm})$ (Figs. 1a-b). IRC was packed incrementally using an instrument and pre-polymerized at each increment $(2+2+1 \mathrm{~mm}$, respectively) for $10 \mathrm{~s}$ (GC Steplight SL-1,Gradia Indirect, GC America). After the cavity 
was filled, the final polymerization was achieved (GC Labolight LV-III, Gradia Indirect, GC America) for 3 minutes. Each specimen surface was finished using 320, 400 and 600 grit silicon carbide papers in sequence under water irrigation.

Surface conditioning methods

Control group: In the control group, IRC surfaces were finished using 320, 400 and 600 grit silicon carbide paper in sequence under water irrigation, etched with $35 \%$ $\mathrm{H}_{3} \mathrm{PO}_{4}$ for $60 \mathrm{~s}$ and rinsed and dried.

Air-abrasion group: IRC surfaces were air-abraded using $50 \mu \mathrm{m} \quad \mathrm{Al}_{2} \mathrm{O}_{3}$ particles (Easyblast, Bego, Bremen, Germany) for $10 \mathrm{~s}$ at 2.8 bar pressure from $10 \mathrm{~mm}$ distance. The specimen surfaces were then air-sprayed.

Tribochemical silica coating: In this group, IRC surfaces were air-abraded first using $110 \mu \mathrm{m} \mathrm{Al}_{2} \mathrm{O}_{3}$ particles (Rocatec-Pre powder, 3M ESPE, Minn, USA) and then with $110 \mu \mathrm{m}$ alumina particles coated with silica (Rocatec-Plus, 3M ESPE) both for $10 \mathrm{~s}$ from a distance of $10 \mathrm{~mm}$ at 2.8 bar. The specimen surfaces were then air-sprayed. Hydrofluoric acid etching: In this group, IRC surfaces were etched with $9.6 \%$ hydrofluoric acid (Pulpdent, Porcelain Etch Gel, Watertown, MA, USA) for 60 s, washed and dried.

Luting procedures with adhesive cements

Direct resin composite specimens ( $N=192)$ (AELITE, Bisco, Shaumburg, IL, USA; Incisal shade) were fabricated. Adhesive cements were applied on the IRC surfaces and the direct composite specimens were pressed on the IRC, using a teflon mould $(1.3 \times 40 \times 50 \mathrm{~mm})$ with holes of $2.2 \mathrm{~mm}$ diameter holes (Fig. 1c). They were then photo-polymerized (Demetron LED, Kerr Dental Corporation, Orange, CA, USA). 
According to the manufacturer's instructions, Multilink, Panavia F2.0 and Resicem were assigned as "conventional resin cements" as they require only application of specific silane coupling agent on the IRC surfaces.

Multilink group: After application of silane (Monobond Plus, Ivoclar Vivadent, Schaan, Liechtenstein) to the IRC surfaces, it was allowed to reach with the surface for $60 \mathrm{~s}$ and air-dried for $5 \mathrm{~s}$. On the direct composite surfaces, primer (Multilink Primer A and B) was applied after mixing in a ratio of $1: 1$. Primer was allowed to react with the surface for $15 \mathrm{~s}$ and air-dried for $5 \mathrm{~s}$.

Panavia F2.0 group: Primer (Clearfil Ceramic Primer, Kuraray, Tokyo, Japan) was applied to the IRC surfaces and dried with air. In this group, on the direct resin composite surfaces primer (ED Primer II liquid A and B, Kuraray) was applied after mixing at a ratio of $1: 1$. Primer was allowed to react with the surface for $30 \mathrm{~s}$ and airdried for $5 \mathrm{~s}$.

Resicem group: Silane (Monobond Plus, Ivoclar Vivadent, Schaan, Liechtenstein) was applied to the IRC surfaces and let react for $10 \mathrm{~s}$. The surfaces were then air-dried for $5 \mathrm{~s}$.

In the RelyX U100, Speedcem and Gcem groups, no additional silane or primer was applied.

IRC-resin cement-composite assemblies were bonded under pressure $(550 \pm 10 \mathrm{~g})$ for $20 \mathrm{~s}$ using the specimen fixator (Ultradent test appliance, Ultradent, South Jordan, UT, USA) (Figs. 1d-e). After removing from the pressure, specimens were photopolymerized initially for $20 \mathrm{~s}$ from 4 directions (Demetron LED). Light output was controlled using a radiometer (Hilux Ledmax Light Curing Meter, Inc., Piedmont, SD, USA) after every five specimens. The specimens were stored in distilled water for $24 \mathrm{~h}$ at room temperature after fabrication. 
Testing procedures and failure analysis

Bonded specimens were subjected to shear load using a load cell of $40 \mathrm{~N}$ (ESIT, SPA50, ESIT Electronics Ltd., Istanbul, Turkey) in a Universal Testing Machine (MTS Mini-Bionics II, Model 858, MTS Corporation, Eden Prairie, MN, USA) until failure at a cross-head speed of $0.5 \mathrm{~mm} / \mathrm{min}$. Force values obtained during the shear tests were used to calculate the shear bond $(\mathrm{T}=\mathrm{F} / \mathrm{A})$.

After debonding, failure types were examined under a stereomicroscope (Olympus SZ61, Olympus KeyMed Group of Companies, Tokyo, Japan) at x30 magnification and classified as adhesive, cohesive in IRC, cohesive in direct composite or mixed.

Statistical analysis

Bond strength data were statistically analyzed using software (NCSS 2007 \& PASS 2008 Statistical Software, Kaysville, Utah, USA). Kolmogorov-Smirnov and ShapiroWilk tests were used to test normal distribution of the data. As the data (MPa) were normally distributed, 1-way, 2-way analysis of variance (ANOVA) were applied to analyze possible significant differences between the groups with bond strength (MPa) as the dependant variable and surface conditioning methods (4 levels: Control, alumina air-abrasion, tribochemical silica coating and hydrofluoric acid) and cement types (6 levels: Panavia F 2.0, Multilink, Resicem, Speed Cem, RelyX U100, Gcem) as the independent factors. Multiple comparisons were made using Tukey`s post-hoc test. Maximum likelihood estimation without a correction factor was used for 2parameter Weibull distribution, including the Weibull modulus, scale $(m)$ and shape $(0)$, to interpret predictability and reliability of adhesion (Minitab Software V.16, State College, PA, USA). $P<0.05$ was considered to be statistically significant in all tests.

\section{Results}


The bond strength results (MPa) were significantly affected by the surface conditioning method $(p<0.001)$ and the cement type $(p<0.001)$. Interaction terms were also significant $(p<0.001)$.

Compared to the control group of each resin cement, all surface conditioning methods tested increased the bond strength results significantly $(p<0.001)$ (Table 2 , Fig. 2).

For two of the conventional resin cements (Panavia F2.0, Resicem), air-abrasion with $50 \mu \mathrm{m} \mathrm{Al} \mathrm{O}_{3}$ significantly increased the results $(22.6 \pm 6.5,26.2 \pm 6.5$, respectively) compared to the other conditioning methods $(13.6 \pm 1.4-21.9 \pm 3.1)$ but for Multilink, hydrofluoric acid etching (20.5 \pm 3.5$)$ showed significantly higher results compared to those of other methods $(9.4 \pm 4.6-14.2 \pm 5.7)(p<0.01)$.

For the self-adhesive resin cements (Speed Cem, RelyX U100, Gcem), air-abrasion with $50 \mu \mathrm{m} \mathrm{Al} \mathrm{O}_{3}$ significantly increased the results compared to other conditioning methods, except for RelyX U100 where air-abrasion with alumina $(20.3 \pm 2.4)$ or silica $(21.3 \pm 4.5)$ did not show significant difference $(p>0.05)$.

Weibull distribution presented the highest shape (0) for Multilink (7.22) and RelyX U100 (6.16) in the control group (Table 3). After air-abrasion with $50 \mu \mathrm{m} \mathrm{Al} 2 \mathrm{O}_{3}$, Gcem, (11.64) followed by RelyX U100 (9.05) and SpeedCem (8.29) presented reliable adhesion results.

In the control group, failure types were exclusively adhesive with all resin cements. The incidence of cohesive failure in the IRC was the highest with RelyX U100 (100\%) and Speedcem (100\%) after $50 \mu \mathrm{m} \mathrm{Al}_{2} \mathrm{O}_{3}$ air-abrasion (Table 4).

\section{Discussion}


This study was aimed to evaluate the adhesion of conventional and self-adhesive resin cements to IRCs using different surface conditioning methods. Based on the results of this study, since the surface conditioning methods and the cement types significantly affected the results, both null hypothesis tested could be rejected.

IRCs present higher degree of conversion resulting in favourable physical properties $[17,18]$ but this property at the same time yields to less reduced chemical adhesion of resin-based materials to the IRCs $[15,19]$. Most of the adhesive resins used in clinical procedures are expected to deliver shear bond strengths of at least 17 to $20 \mathrm{MPa}$ in order to overcome the polymerization shrinkage stresses in the resin composite [20]. However, in several studies the bond strength was lower than those suggested values [21-23]. In the present study, the mean bond strengths for both $\mathrm{Al}_{2} \mathrm{O}_{3}$ air-abraded and tribochemically silica-coated group in general exceeded the value of $20 \mathrm{MPa}$. More commonly observed cohesive failures observed in these groups signify that this value exceeds that of the cohesive strength of the IRC tested.

The shear bond test is one of the most commonly used bond strength tests [24-26]. In fact, the stresses at restoration-cement interfaces are complex $[27,28]$. Shear stresses are postulated to cause major stresses in clinical failures of restorative materials [29]. The use of bond strength data, based on static load-to-failure tests should be restricted to comparisons of relative effects of material properties, material microstructure and treatment conditions that may enhance their resistance to fracture [30]. In that respect, the cohesive failures are desirable since bond values causing such failures indicate that they exceeded the cohesive strength of the material that is the bond strength between increments of the resin composite. When the composite resin is polished, contaminated, processed in the laboratory or aged, the adhesion to a new composite is reduced by 25 to $80 \%$ of the original cohesive strength [1]. 
Therefore, surface conditioning methods are crucial to improve the resin-resin adhesion.

The bond between the IRC and the resin cement tested in this study may be compared to the repair of an aged resin composite to a new one where interfacial bond results showed decreased values ranging from 25 to $74 \%$ of the original cohesive strength of the substrate composite [30]. Although surface conditioning plays a key role in composite repair strength [31,32], the use of intermediate adhesive resin ensures increased wettability between the composite resins [4]. The use of unfilled low-viscosity intermediate adhesive resin can improve the bonding, irrespective of the surface texture created by different surface conditioning methods [33,34]. Previous studies in this regard are controversial. While some did not find any significant effect of the adhesive resin monomer and silane coupling agent materials [25], others reported the opposite $[35,36]$. In this study the silane coupling agents, primers of the corresponding resin cements were used subsequent to the surface conditioning methods.

In general surface conditioning with $50 \mu \mathrm{m} \mathrm{Al}_{2} \mathrm{O}_{3}$ air-abrasion provided favourable results compared to other conditioning methods. The roughened surface facilitates micromechanical interlocking and improves the adhesive properties of IRCs [1]. Although air-abrasion improves adhesion in repair actions, it may damage the margins of restorations made of IRCs [36-40]. Hence, the use of small particle size such as 50 $\mu \mathrm{m} \mathrm{Al}_{2} \mathrm{O}_{3}$ should be preferred to $110 \mu \mathrm{m} \mathrm{Al}_{2} \mathrm{O}_{3}$ or silica. Moreover, air-abrasion exposes the particles on the surface that eventually facilitates the silanization on larger area of filler particles [5]. This could be also the reason for favourable results obtained in most of the resin cements after air-abrasion. 
Previous studies had shown that hydrofluoric acid etching removes the oxygen inhibited layer of resin composite and weaken the filler particle-matrix interface. The dissolved glass filler particles on the IRC surface then generates micromechanical retention $[37,41]$. Silane application after hydrofluoric acid etching would enhance the bond strength owing to filler particles at the surface presenting potential sites for silanization [1]. According to some studies, etching could also cause total dissolution of exposed inorganic filler particles [1,5,36,41]. In such a situation, IRC-cement adhesive interface becomes less resistant to debonding forces. Interestingly however, hydrofluoric acid etching resulted in significantly higher bond strength results for Multilink conventional resin cement compared to those of other conditioning methods. This could be attributed to the co-polymerization achieved with the silane (Monobond Plus) and the primers used, (Multilink Primer A and B). Further microscopy analysis should verify the effect of hydrofluoric acid on the IRC tested.

In the tribochemical silica-coating method, alumina particles embedded in silica forms silica-modified surface that is more reactive to the resin after silane application. Silane molecules react with water and forms silanol groups that form siloxane network with the silica surface. Monomeric ends of the silane molecules then react with methacrylate groups of the adhesive resins through a free radical polymerization process. In this study, bond strength results with air-abrasion with $110 \mu \mathrm{m}$ silica or 50 $\mu \mathrm{m} \mathrm{Al}_{2} \mathrm{O}_{3}$ were either similar or higher with the latter. Similar observations were made in previous studies $[39,40]$. However, after aging conditions, the achieved bond strength was reported to be higher with silica-coating than with alumina $[42,43]$. Further studies should study the effect of aging of adhesion between tested cements and the IRC. The majority of the cements demonstrated higher bond strength with 50 $\mu \mathrm{m} \mathrm{Al}_{2} \mathrm{O}_{3}$ than with silica-coating. This could be explained by the high particle size of 
silica $(110 \mu \mathrm{m})$, creating an irregular roughened surface, eventually leading to decreased wettability of the silane in the deepest parts of the roughened area [44]. This finding is also supported with Weilbull characteristics that resulted in more reliable adhesion after air-abrasion with $50 \mu \mathrm{m} \mathrm{Al} \mathrm{O}_{3}$ compared to $110 \mu \mathrm{m}$ silica. Nevertheless, both air-abrasion methods displayed more cohesive failures in the IRC compared to the control and hydrofluoric acid etched groups that mainly showed adhesive failure. It has to be noted that in this study, in an attempt to avoid heterogeneity in dentin structure, IRCs were cemented on resin composite. Thus, the clinical implication of this study accounts for situations where IRCs are bonded to resin composites. The adhesive performance of the cements should be further tested in IRC-cement-dentin assemblies in a larger sample.

Currently, limited clinical information is available on the longevity of IRCs [45]. Thus, the results of this study could be implemented in cementation protocols when IRCs are indicated.

\section{Conclusions}

From this study, the following could be concluded:

1. The indirect resin composite material tested benefitted from surface conditioning methods for improved adhesion of both conventional and self-adhesive resin cements.

2. From conventional resin cements tested, Panavia F2.0, Resicem presented improved adhesion after air-abrasion with $50 \mu \mathrm{m} \mathrm{Al}_{2} \mathrm{O}_{3}$ compared to those of the other conditioning methods whereas for Multilink, hydrofluoric acid etching provided higher results. 
3. All self-adhesive resin cements tested (Speed Cem, RelyX U100, Gcem) benefitted from air-abrasion with $50 \mu \mathrm{m} \mathrm{Al}_{2} \mathrm{O}_{3}$ compared to other conditioning methods but for RelyX U100 both alumina and silica air-abrasion presented similar results.

4. Weilbull characteristics indicated more reliable adhesion after air-abrasion with $50 \mu \mathrm{m} \mathrm{Al}_{2} \mathrm{O}_{3}$ for Gcem, (11.64) followed by RelyX U100 (9.05) and SpeedCem (8.29).

5. Cohesive failures in the indirect resin composite were the most predominant in groups cemented with RelyX U100 and Speedcem after $50 \mu \mathrm{m} \mathrm{Al} \mathrm{O}_{3}$ air-abrasion.

\section{Clinical Relevance}

Self-adhesive resin cement, RelyX U100, applied after $50 \mu \mathrm{m} \mathrm{Al} \mathrm{O}_{3}$ air-abrasion in its dual polymerized mode would deliver more reliable adhesion.

\section{Disclosure}

The authors state that they have no conflicts of interest. 


\section{References}

1. D'Arcangelo C, Vanini L. Effect of surface treatments on the adhesive properties of indirect composite restorations. J Adhes Dent 2007;9:319-326.

2. Burke FJT, Qualtrough AJ. Tooth colored inlays: State of the art. J Ir Dent Assoc 1992;38:2-6.

3. Mandikos MN, McGivney GP, Davis E, Bush PJ, Carter JM. A comparison of the wear resistance and hardness of indirect composite resins. J Prosthet Dent 2001;85:386-395.

4. Rathke A, Tymina $Y$, Haller B. Effect of different surface treatments on the composite-composite repair bond strength. Clin Oral Investig 2009;13:317-323.

5. Soares CJ, Giannini M, Oliveira MT, Paulillo LAMS, Martins LRM. Effects of surface treatments of laboratory-fabricated composites on the microtensile bond strength to a luting resin cement. J Appl Oral Sci 2004;12:45-50.

6. Swift Jr EJ, Brodeur C, Cvitko E, Pires JAF. Treatment of composite surfaces for indirect bonding. Dent Mater 1992;8:193-196.

7. Latta MA, Barkmeier WW. Bond strength of a resin cement to a cured composite inlay material. J Prosthet Dent 1994;72:189-193.

8. Imamura GM, Reinhardt JW, Boyer DB, Swift Jr EJ. Enhancement of resin bonding to heat-cured composite resin. Oper Dent 1996;21:249-256.

9. Shortall AC, Baylis RL, Wilson HJ. Composite inlay/luting resin bond strengthsurface treatment effects. J Dent 1996;24:129-135.

10. Paffenbarger GC, Swenney WT, Bowen RL. Bonding porcelain teeth to acrylic resin denture bases. J Am Dent Assoc 1967;74:753-754.

11. Yoshida K, Greener EH, Lautenschlager EP. Shear bond strengths of two resin luting cements to laboratory-cure prosthetic composite resin. Am J Dent 1993;6:13-16. 
12. Lin CT, Lee SY, Keh ES, Dong DR, Huang HM, Shih YH. Influence of silanization and filler fraction on aged dental composites. J Oral Rehabil 2000;27:919-926.

13. Papacchini F, Dall'Oca S, Chieffi N, Goracci C, Sadek FT, Suh BI, Tay FR, Ferrari M. Composite-to-composite microtensile bond strength in the repair of a microfilled hybrid resin: effect of surface treatment and oxygen inhibition. J Adhes Dent 2007;9:25-31.

14. Özcan M, Alander P, Valittu PK, Huysmans MC, Kalk W. Effect of three surface conditioning methods to improve bond strength of particulate filler resin composites. $\mathrm{J}$ Mater Sci Mater Med 2005;16:21-27.

15. Tam LE, Mc Comb D. Shear bond strengths of resin luting cement to laboratorymade composite resin veneers. J Prosthet Dent 1991;66:314-321.

16. Matsumura $H$, Kato $H$, Atsuta $M$. Shear bond strength to feldspathic porcelain of two luting cements in combination with three surface treatments. J Prosthet Dent 1997;78:511-517.

17. Swift EJ, Sturdevant JR, Ritter AV. Class I and II indirect tooth-colored restorations. In: Roberson TM, Heymann HO, Swift EJ Jr, editors. Art and science of operative dentistry. Saint Louis: Mosby; 2006. 5th ed. p.603-622.

18. Türkmen $C$, Durkan $M$, Cimilli $H$, Öksüz $M$. Tensile bond strength of indirect composites luted with three new self-adhesive resin cements to dentin. J Appl Oral Sci 2011;19:363-369.

19. DeSchepper EJ, Tate TH, Powers JM. Bond strength of resin cements to microfilled composites. Am J Dent 1993;6:235-238.

20. Davidson CL, de Gee AJ, Feilzer A. The competition between the compositedentin bond strength and the polymerization contraction stress. J Dent Res 1984;63:1396-1399. 
21. Chang JC, Hart DA, Estey AW, Chan JT. Tensile bond strengths of five luting agents to two CAD-CAM restorative materials and enamel. J Prosthet Dent 2003;90:18-23.

22. Üşümez A, Aykent F. Bond strengths of porcelain laminate veneers to tooth surfaces prepared with acid and Er,Cr:YSGG laser etching. J Prosthet Dent 2003;90:24-30.

23. Perdigao J, Gomes G, Gondo R, Fundingsland JW. In vitro bonding performance of all-in-one adhesives. Part 1 - microtensile bond strengths. J Adhes Dent 2006;8:367-373.

24. Söderholm K-JM. Correlation of in vivo and in vitro performance of adhesive materials: a report of the ASC MD 156 task group on test methods for adhesion of restorative materials. Dent Mater 1991;7:74-83.

25. Swift EJ, Perdigao J, Heymann HO. Bonding to enamel and dentine: a brief history and state of art. Quintessence Int 1995;26:95-110.

26. Dérand $P$, Dérand $T$. Bond strength of luting cements to zirconium oxide ceramics. Int J Prosthodont 2000;13:131-135.

27. Mota CS, Demarco FF, Camacho GB, Powers JM. Tensile bond strength of four resin luting agents bonded to bovine enamel and dentin. J Prosthet Dent 2003;89:558564.

28. Ernst $\mathrm{CP}$, Cohnen $\mathrm{U}$, Stender E, Willerhausen B. In vitro retentive strength of zirconium oxide ceramic crowns using different luting agents. J Prosthet Dent 2005;93:551-558.

29. Ersu B, Yuzugullu B, Ruya YA, Canay S. Surface roughness and bond strengths of glass-infiltrated alumina-ceramics prepared using various surface treatments. J Dent 2009;37:848-856. 
30. DeHoff PH, Annusavice KJ, Wang Z. Three-dimensional finite element analysis of the shear bond test. Dent Mater 1995;11:126-131.

31. Vankerckhoven $H$, Lambrechts $P$, van Beylen $M$, Davidson $C L$, Vanherle $G$. Unreacted methacrylate groups on the surface of composite resins. J Dent Res 1982;61:791-795.

32. Hummel M, Kern M. Durability of the resin bond strength to the alumina ceramic Procera. Dent Mater 2004;20:498-508.

33. Brosch T, Pilo R, Bichacho N, Blutstein R. Effect of combinations of surface treatments and bonding agents on the bond strength of repaired composites. J Prosthet Dent 1997;77:122-126.

34. Kallio TT, Lastumaki TM, Vallittu PK. Bonding of restorative and veneering composite resin to some polymeric composites. Dent Mater 2001;17:80-86.

35. Saunders W. Effect of fatigue upon the interfacial bond strength of repaired composite resins. J Dent 1990;18:158-162.

36. El Zohairy AA, De Gee AJ, Mohsen MM, Feilzer AJ. Microtensile bond strength testing of luting cements to prefabricated CAD/CAM ceramic and composite blocks. Dent Mater 2003;19:575-583.

37. Hori S, Minami H, Minesaki Y, Matsumura H, Tanaka T. Effect of Hydrofluoric acid etching on shear bond strength of an indirect resin composite to an adhesive cement. Dent Mater J 2008;27:515-522.

38. Swift Jr EJ, Cloe BC, Boyer DB. Effect of a silane coupling agent on composite repair strengths. Am J Dent 1994;7:200-202.

39. Borges GA, Sophr AM, De Goes MF, Sobrinho LC, Chan DCN. Effect of etching and airborne particle abrasion on the microstructure of different dental ceramics. $J$ Prosthet Dent 2003;89:479-488. 
40. Fawzy AS, El-Askary FS, Amer MA. Effect of surface treatments on the tensile bond strength of repaired water aged anterior restorative micro-fine hybrid resin composite. J Dent 2008;36:969-976.

41. Soares CJ, Soares PV, Pereira JC, Fonseca RB. Surface treatment protocols in the cementation process of ceramic and laboratory-processed composite restorations: a literature review. J Esthet Restor Dent 2005;7:224-235.

42. Pontes AP, Oshima HM, Pacheco JF, Martins JL, Shinkai RS. Shear bond strength of direct composite repairs in indirect composite systems. Gen Dent 2005;53:343-347.

43. Valandro LF, Pelogia F, Galhano G, Bottıno MA, Mallmann A. Surface conditioning of a composite used for inlay/onlay restorations: Effect on $\mu$ TBS to Resin Cement. J Adhes Dent 2007;9:495-498.

44. Brendeke J, Özcan M. Effect of physico-chemical aging conditions on the composite-composite repair bond strength. J Adhes Dent 2007;9:399-406.

45. Morimoto S, Rebello de Sampaio FB, Braga M, Sesma N, Özcan M. Survival and complication rates of resin and ceramic inlays, onlays and overlays: a systematic review and meta-analysis. J Dent Res 2016 (Epub). 


\section{Captions to tables and figures:}

\section{Tables:}

Table 1. The brands, types, manufacturers, chemical compositions and batch numbers of the materials used in this study.

Table 2. Mean shear bond strengths, standard deviations (MPa) and significant differences between resin cements bonded to indirect resin composite after various surface conditioning methods. Different upper case superscript letters indicate statistically significant differences in row column and different lower case superscript letters in one row (Two-way ANOVA, Tukey`s tests, $\left.{ }^{*} p<0.05\right)$.

Table 3. Weibull parameters (shape and scale values) $(95 \% \mathrm{Cl})$ for all experimental groups using maximum likelihood estimation.

Table 4. Distribution of failure types per experimental group.

\section{Figures:}

Figs. 1a-e a) Silicone mould $(25 \times 20 \mathrm{~mm})$ used for the preparation of the acrylic resin block, b) acrylic resin block dublicated, c) teflon mold $(1.3 \times 40 \times 50 \mathrm{~mm})$ with $2.2 \mathrm{~mm}$ diameter holes used for preparing the direct resin composites, d) Ultradent device used for stabilizing the resin components during bonding, e) final bonded specimen.

Fig. 2 Graphical presentation of the mean shear bond strengths of resin cements bonded to indirect resin composite after various surface conditioning methods. 


\section{Tables:}

\begin{tabular}{|c|c|c|c|c|}
\hline Brands & Cement Type & Manufacturer & Chemical Composition & Batch Number \\
\hline $\begin{array}{l}\text { Gradia } \\
\text { Indirect }\end{array}$ & $\begin{array}{l}\text { Indirect Resin } \\
\text { Composite }\end{array}$ & $\begin{array}{c}\text { GC Corporation, Tokyo, } \\
\text { Japan }\end{array}$ & $\begin{array}{c}\text { bis-(methacryloyloxy)- } \\
\text { propoxycarbonylaminohexane- } \\
\text { triazine-trione, } \\
\text { aluminoborosilicate and } 75 \% \\
\text { silica fillers }\end{array}$ & 0902181 \\
\hline $\begin{array}{l}\text { Panavia } \\
\text { F2.0 }\end{array}$ & $\begin{array}{c}\text { Conventional Resin } \\
\text { Cement }\end{array}$ & $\begin{array}{l}\text { Kuraray Medical Inc., } \\
\text { Okayama, Japan }\end{array}$ & $\begin{array}{l}\text { Methacrylate, MDP, quartz- } \\
\text { glass, microfiller, photoinitiator } \\
\text { methacrylate, barium glass, } \\
\text { sodiumfluoride, chemical } \\
\text { initiator }\end{array}$ & $\begin{array}{l}\text { A-Paste: 00371A } \\
\text { B-Paste: } 00197 \mathrm{~A}\end{array}$ \\
\hline Resicem & $\begin{array}{c}\text { Conventional Resin } \\
\text { Cement }\end{array}$ & Shofu Inc., Kyoto, Japan & $\begin{array}{l}\text { UDMA, TEGDMA, HEMA, 4- } \\
\text { AET, fluoroaluminosilicate } \\
\text { glass, initiator, others }\end{array}$ & 040958 \\
\hline Multilink & $\begin{array}{c}\text { Conventional Resin } \\
\text { Cement }\end{array}$ & $\begin{array}{c}\text { Ivoclar Vivadent, Schaan, } \\
\text { Liechtenstein }\end{array}$ & $\begin{array}{c}\text { Self dimethacrylateand HEMA, } \\
\text { barium glass filler, } \\
\text { silicondioxide filler, } \\
\text { ytterbiumtrifluoride, catalysts } \\
\text { and stabilizers, pigments }\end{array}$ & M28042 \\
\hline Speed Cem & $\begin{array}{l}\text { Self-adhesive } \\
\text { Resin Cement }\end{array}$ & Ivoclar Vivadent & $\begin{array}{c}\text { Dimethacrylates, } \\
\text { methacrylatedphosphoricesters } \\
\text {, barium glass, } \\
\text { ytterbiumtrifluoride, } \\
\text { copolymers, high dispersed } \\
\text { silica, initiators, catalysts and } \\
\text { stabilizers }\end{array}$ & M39162 \\
\hline RelyX U100 & $\begin{array}{c}\text { Self-adhesive Resin } \\
\text { Cement }\end{array}$ & $\begin{array}{l}\text { 3M ESPE, Seefeld, } \\
\text { Germany }\end{array}$ & $\begin{array}{l}\text { Glass powder, methacrylated } \\
\text { phosphoric acid esters, } \\
\text { triethyleneglycoldimethacrylate } \\
\text { (TEG-DMA), silane treated } \\
\text { silica, sodiumpersulfate }\end{array}$ & 358639 \\
\hline GCem & $\begin{array}{l}\text { Self-adhesive } \\
\text { Resin Cement }\end{array}$ & GC Corporation & $\begin{array}{c}\text { Fluoroaminosilicate glass, } \\
\text { initiator, pigment, 4-MET, } \\
\text { phosphoricacid ester, } \\
\text { monomer, water, UDMA, } \\
\text { dimethacrylate, silica powder, } \\
\text { initiator, stabilizer }\end{array}$ & 0901291 \\
\hline
\end{tabular}

Table 2. The brands, types, manufacturers, chemical compositions and batch numbers of the materials used in this study. 


\begin{tabular}{|c|c|c|c|c|}
\hline $\begin{array}{l}\text { Surface } \\
\text { Conditioning } \\
\text { Method }\end{array}$ & Control group & $\begin{array}{l}\text { Tribochemical } \\
\text { silica-coating }\end{array}$ & $\begin{array}{l}\text { Hydrofluoric } \\
\text { acid etch }\end{array}$ & $\mathrm{Al}_{2} \mathrm{O}_{3}$ air-abrasion \\
\hline & Mean \pm SD & Mean $\pm S D$ & Mean $\pm S D$ & Mean $\pm S D$ \\
\hline Resicem & $\underline{10 \pm 6.8^{\mathrm{A}, \mathrm{a}}}$ & $\underline{21.9 \pm 3.1^{\mathrm{B}, \mathrm{c}}}$ & $\underline{14.9 \pm 5.1^{\mathrm{A}, \mathrm{B}, \mathrm{a}}}$ & $26.2 \pm 6.5^{\mathrm{C}, \mathrm{a}}$ \\
\hline Panavia F2.0 & $\underline{10.5 \pm 4.4^{\mathrm{A}, \mathrm{a}}}$ & $\underline{18.3 \pm 3.9^{A, B, b}}$ & $\underline{13.6 \pm 1.4^{\mathrm{A}, \mathrm{a}}}$ & $\underline{22.6 \pm 6.52^{\mathrm{B}, \mathrm{C}, \mathrm{a}}}$ \\
\hline Gcem & $\underline{7.8 \pm 3.7^{\mathrm{A}, \mathrm{a}}}$ & $\underline{10.3 \pm 3.9^{A, B, a}}$ & $\underline{11.2 \pm 3.6^{\mathrm{A}, \mathrm{B}, \mathrm{a}}}$ & $\underline{15.8 \pm 2.1^{\mathrm{C}, \mathrm{c}}}$ \\
\hline Multilink & $\underline{12.1 \pm 2.4^{\mathrm{A}, \mathrm{a}}}$ & $\underline{9.4 \pm 4.6^{\mathrm{A}, \mathrm{a}}}$ & $20.5 \pm 3.5^{\mathrm{B}, \mathrm{b}}$ & $\underline{14.2 \pm 5.7^{\mathrm{A}, \mathrm{c}}}$ \\
\hline RelyX U 100 & $\underline{13.8 \pm 2.7^{\mathrm{A}, \mathrm{a}}}$ & $\underline{21.3 \pm 4.5^{\mathrm{B}, \mathrm{c}}}$ & $\underline{14.8 \pm 2.1^{\mathrm{A}, \mathrm{a}}}$ & $\underline{20.3 \pm 2.4^{\mathrm{B}, \mathrm{b}}}$ \\
\hline SpeedCem & $\underline{11.3 \pm 5.3^{\mathrm{A}, \mathrm{a}}}$ & $18.2 \pm 3.3^{\mathrm{B}, \mathrm{b}}$ & $\underline{16.2 \pm 1.6^{\mathrm{A}, \mathrm{B}, \mathrm{C}}}$ & $25.5 \pm 4^{\mathrm{C}, \mathrm{a}}$ \\
\hline
\end{tabular}

Table 2. Mean shear bond strengths, standard deviations (MPa) and significant differences between resin cements bonded to indirect resin composite after various surface conditioning methods. Different upper case superscript letters indicate statistically significant differences in row column and different lower case superscript letters in one row (Two-way ANOVA, Tukey`s tests, ${ }^{*} \mathrm{p}<0.05$ ). 


\begin{tabular}{|c|c|c|c|c|c|c|c|c|}
\hline & \multicolumn{2}{|c|}{ Control } & \multicolumn{2}{|c|}{$\begin{array}{l}\text { Tribochemical } \\
\text { silica-coating }\end{array}$} & \multicolumn{2}{|c|}{$\begin{array}{l}\text { Hydrofluoric } \\
\text { Acid }\end{array}$} & \multicolumn{2}{|c|}{$\begin{array}{l}\mathrm{Al}_{2} \mathrm{O}_{3} \\
\text { air-abrasion }\end{array}$} \\
\hline & Shape & Scale & Shape & Scale & Shape & Scale & Shape & Scale \\
\hline Resicem & 1.608 & 46.70 & 8.977 & 103.0 & 3.090 & 73.82 & 4.959 & 127.1 \\
\hline $\begin{array}{l}\text { Panavia } \\
\text { F2.0 }\end{array}$ & 2.834 & 52.54 & 5.166 & 88.42 & 11.29 & 63.28 & 4.262 & 111.0 \\
\hline Gcem & 2.475 & 39.32 & 3.107 & 51.15 & 4.243 & 54.99 & 11.64 & 73.93 \\
\hline Multilink & 7.224 & 57.65 & 2.342 & 47.31 & 6.612 & 97.54 & 3.063 & 70.70 \\
\hline RelyX & 6.164 & 65.88 & 5.606 & 102.5 & 10.39 & 69.41 & 9.048 & 95.09 \\
\hline $\begin{array}{l}\text { Speed } \\
\text { Cem }\end{array}$ & 2.522 & 56.91 & 10.66 & 85.28 & 11.62 & 75.13 & 8.295 & 120.5 \\
\hline
\end{tabular}

Table 3. Weibull parameters (shape and scale values) $(95 \% \mathrm{Cl})$ for all experimental groups using maximum likelihood estimation. 


\begin{tabular}{|c|c|c|c|c|}
\hline Failure Type & Control & $\begin{array}{l}\text { Tribochemical } \\
\text { silica-coating }\end{array}$ & $\begin{array}{l}\text { Hydrofluoric } \\
\text { acid etch }\end{array}$ & $\begin{array}{l}\mathrm{Al}_{2} \mathrm{O}_{3} \\
\text { air-abrasion }\end{array}$ \\
\hline & n (\%) & n (\%) & n (\%) & n (\%) \\
\hline Adhesive & $7(100)$ & $0(0)$ & $6(75)$ & $1(12.5)$ \\
\hline Mixed & $0(0)$ & $5(62.5)$ & $1(12.5)$ & $0(0)$ \\
\hline $\begin{array}{l}\text { Cohesive } \\
\text { in IRC }\end{array}$ & $0(0)$ & $3(37.5)$ & $1(12.5)$ & $7(87.5)$ \\
\hline Adhesive & $7(100)$ & $0(0)$ & $1(12.5)$ & $2(25)$ \\
\hline Mixed & $0(0)$ & $5(62.5)$ & $7(87.5)$ & $3(37.5)$ \\
\hline $\begin{array}{l}\text { Cohesive } \\
\text { in IRC }\end{array}$ & $0(0)$ & $3(37.5)$ & $0(0)$ & $3(37.5)$ \\
\hline Adhesive & $7(100)$ & $0(0)$ & $6(75)$ & $8(100)$ \\
\hline Mixed & $0(0)$ & $2(25)$ & $2(25)$ & $0(0)$ \\
\hline $\begin{array}{l}\text { Cohesive } \\
\text { in IRC }\end{array}$ & $0(0)$ & $4(50)$ & $0(0)$ & $0(0)$ \\
\hline Adhesive & $7(100)$ & $0(0)$ & $5(62.5)$ & $7(87.5)$ \\
\hline Mixed & $0(0)$ & $1(12.5)$ & $3(37.5)$ & $1(12.5)$ \\
\hline $\begin{array}{l}\text { Cohesive } \\
\text { in IRC }\end{array}$ & $0(0)$ & $5(62.5)$ & $0(0)$ & $0(0)$ \\
\hline Adhesive & $7(100)$ & $0(\% 0)$ & $8(100)$ & $2(\% 25,0)$ \\
\hline Mixed & $0(0)$ & $8(\% 100)$ & $0(0)$ & $0(\% 0)$ \\
\hline $\begin{array}{l}\text { Cohesive } \\
\text { in IRC }\end{array}$ & $0(0)$ & $0(\% 0)$ & $0(0)$ & $6(\% 75,0)$ \\
\hline Adhesive & $7(100)$ & $0(\% 0)$ & $5(62.5)$ & $0(\% 0)$ \\
\hline Mixed & $0(0)$ & $6(\% 75,0)$ & $3(37.5)$ & $0(\% 0)$ \\
\hline $\begin{array}{l}\text { Cohesive } \\
\text { in IRC }\end{array}$ & $0(0)$ & $2(\% 25,0)$ & $0(0)$ & $8(\% 100)$ \\
\hline
\end{tabular}

Table 4. Distribution of failure types per experimental group. 


\section{Figures:}

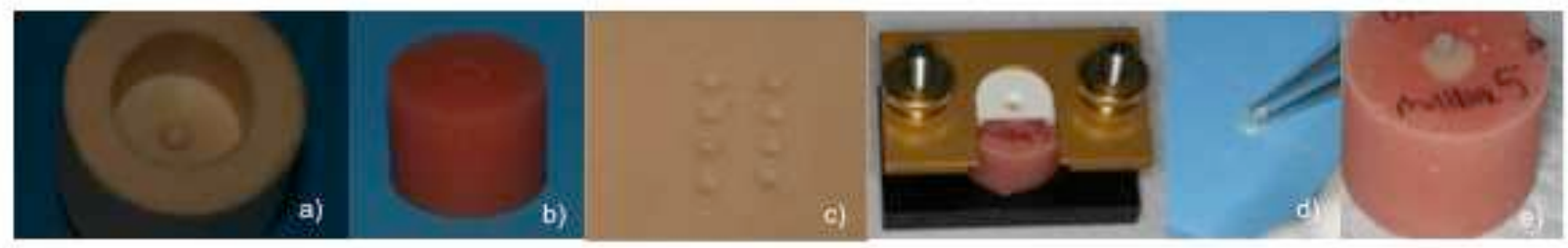

Figs. 1a-e a) Silicone mould $(25 \times 20 \mathrm{~mm})$ used for the preparation of the acrylic resin block, b) acrylic resin block dublicated, c) teflon mold $(1.3 \times 40 \times 50 \mathrm{~mm})$ with $2.2 \mathrm{~mm}$ diameter holes used for preparing the direct resin composites, d) Ultradent device used for stabilizing the resin components during bonding, e) final bonded specimen.



Fig. 2 Graphical presentation of the mean shear bond strengths of resin cements bonded to indirect resin composite after various surface conditioning methods. 